OPEN ACCESS

Edited by:

Pei Sun,

Tsinghua University, China

Reviewed by:

Usman Ghani,

Iqra University, Pakistan

Hussain Dawood,

Jeddah University, Saudi Arabia

*Correspondence: Muhammad Azeem Ashraf azeem20037@gmail.com

Specialty section: This article was submitted to Educational Psychology, a section of the journal Frontiers in Psychology

Received: 31 December 2020 Accepted: 29 April 2021 Published: 31 May 2021

Citation: Khan MN, Ashraf MA, Seinen D, Khan KU and Laar RA (2021) Social

Media for Knowledge Acquisition and

Dissemination: The Impact of the COVID-19 Pandemic on Collaborative

Learning Driven Social Media Adoption. Front. Psychol. 12:648253. doi: 10.3389/fpsyg.2021.648253

\section{Social Media for Knowledge Acquisition and Dissemination: The Impact of the COVID-19 Pandemic on Collaborative Learning Driven Social Media Adoption}

\author{
Muhammad Naeem Khan ${ }^{1}$, Muhammad Azeem Ashraf ${ }^{2 *}$, Donald Seinen ${ }^{3}$, \\ Kashif Ullah Khan ${ }^{4}$ and Rizwan Ahmed Laar ${ }^{5}$
}

'School of Social and Behavioral Science, Nanjing University, Nanjing, China, ${ }^{2}$ Research Institute of Educational Science, Hunan University, Changsha, China, ${ }^{3}$ School of Information Management, Nanjing University, Nanjing, China, ${ }^{4}$ School of Management Sciences, Ghulam Ishaq Khan Institute of Engineering Sciences and Technology, Swabi, Pakistan, ${ }^{5}$ School of Sports Science and Physical Education, Nanjing Normal University, Nanjing, China

During the COVID-19 outbreak, educational institutions were closed, and students worldwide were confined to their homes. In an educational environment, students depend on collaborative learning $(\mathrm{CL})$ to improve their learning performance. This study aimed to increase the understanding of social media adoption among students during the COVID-19 pandemic for the purpose of CL. Social media provides a learning platform that enables students to easily communicate with their peers and subject specialists, and is conducive to students' CL. This study addresses the key concept of CL during the COVID-19 pandemic by assessing social media use among students in higher education. The relationship between social media use and students' performance is crucial to understanding the role of social media during a pandemic. This study is based on constructivism theory and the technology acceptance model. Structural equation modeling was used to analyze the conceptual model using SmartPLS. The research findings indicate that social media plays an important role during the pandemic because it provides opportunities for students to enhance CL under the aforementioned situations. This study makes noteworthy theoretical and practical contributions.

Keywords: collaborative learning, COVID-19, electronic-learning, social networking, student community, TAM

\section{INTRODUCTION}

The onset of the COVID-19 outbreak is a historically unparalleled adverse occurrence (Venkatesh, 2020) with unprecedented lockdowns imposed across nations Pandemics are large outbreaks of an infectious disease over a wide geographical area and can result in widespread morbidity and mortality (Madhav et al., 2017). Various governments have imposed restrictions on citizens' movements, canceled social activities, and advised people to stay at home to prevent the spread of COVID-19 (Laato et al., 2020). The grim fact is that thousands of people have experienced and will continue to experience the negative impacts of COVID-19, including its induced constraints (Dwivedi et al., 2020). 
COVID-19 has disrupted many aspects of life, such as the medical system, economy, and education (Li et al., 2020). Educational institutions saw forced closures, and students were required to remain at home. This has led to procedural changes in the day-to-day operations of academic institutions. Because of the pandemic, digital advances have been made in the global higher education sector (Dwivedi et al., 2020). Colleges and universities have canceled classes, and administrators have struggled to convert courses into an online format in a matter of days or weeks (McMurtrie, 2020). To efficiently deliver this online content, educational institutions have created official websites and applications to enable students to continue their education. Several academic institutions have implemented "elearning," a web-based learning ecosystem for the dissemination of information and communication to support instructors in their transition to online learning (McMurtrie, 2020).

During the pandemic, people tended to spend more time on social media (SM) as they practice social distancing. SM sites saw an increase of $61 \%$ in web traffic compared to the typical rates during the first 3 months of the COVID19 outbreak. In the past, students reported that SM adoption is, in part, motivated by the need to contact family, teachers, classmates, colleagues, and friends (Holmes, 2020). SM is a medium of communication that enables teachers and students to communicate through numerous online learning applications while adhering to social distancing regulations (Vordos et al., 2020). Furthermore, during COVID-19, the role of SM for educational purposes has become more significant, as it enhances connectivity and brings collaborative opportunities to people who are now beginning to use SM (Islam et al., 2020). SM tools enable teachers, students, and academic institutions to change their teaching or learning methods in a bid to overcome COVID-19 induced restrictions. With the growth of social networks and the increased online presence of many academic institutions, students enjoy live streaming services through SM (e.g., Instagram, Facebook) whereby they participate in regular discussions on trending topics and keep in touch with peers or instructors via online forums (Abi-Rafeh et al., 2019; Abi-Rafeh and Azzi, 2020). Regarding teaching and learning purposes in the context of assessing education sustainability, researchers have examined the incorporation of learning via SM in the higher education curriculum (Alamri et al., 2020).

Most Pakistani people are increasingly using SM for communication, work, educational purposes, and entertainment. According to the Pakistan Telecommunication Authority (PTA), the overall Internet traffic in the country has increased by $15 \%$, with SM platforms accounting for the largest proportion of this increase (Ramsha, 2020). Due to the ban on public gatherings, Pakistani users want to connect and communicate on Instagram, Facebook, WhatsApp, YouTube, and Twitter, as evidenced by the increase in the number of active users on all platforms during the COVID-19 period (Khan, 2020). Moreover, during March and April 2020, Facebook usage increased from 2.8 to $6.94 \%$ in its Pakistani user base. As offices, schools, and universities become more accessible remotely, the need for messaging connectivity continues to grow. WhatsApp, the most widely used messenger service in Pakistan, saw its usage increase by $23.5 \%$ over the same period at the start of the outbreak (Ramsha, 2020). Most academic institutes provide online classes using different applications, such as Zoom, WhatsApp, and Google Classroom (Adnan, 2020). As per the PTA report, video conferencing calls increased five-fold during COVID19. The data show that on February 26, Zoom users totaled 4,149, while on April 8, its user base reached 84,469. Likewise, the number of Zoom application users increased from 5,404 to over 23,000 over 44 days (Ramsha, 2020). Figure 1 shows the impact of COVID-19 on global education systems. The traditional education system has been tremendously impacted by social distancing and other health-related measures adopted worldwide due to the COVID-19 pandemic. However, online education systems have supported the continuance of education using the already available Internet technology. In this scenario, SM platforms have provided an extensive learning platform to involve individuals in the discussion process related to learning topics among peers and student-teacher interactions. Moreover, SM platforms have helped in learning further topics in the related areas of study. Social media platforms provide an alternative to face-to-face discussions, extensively supporting students worldwide.

During the COVID-19 pandemic, multiple studies have been conducted in various research directions, including SM misinformation (Islam et al., 2020), knowledge dissemination (Chan et al., 2020), social distancing (Greenhow and Chapman, 2020), shaping knowledge (Karasneh et al., 2021), business education (Krishnamurthy, 2020), and games (Laato et al., 2020). In contrast, research on SM adoption for collaborative learning (CL) purposes by students facing the ongoing COVID19 constraints is limited. Therefore, this study's main emphasis lies in the student community adopting the use of SM platforms for CL. Considering the literature gap identified, our study's main objectives were as follows:

- To investigate the factors that trigger SM adoption by the student community during COVID-19.

- To investigate the impact of using social media-based CL on students' learning performance.

- To investigate how students during COVID-19 collaborate with peers by using SM. Based on the study objectives, this study can open up new opportunities to integrate SM into progressive education and to leverage the exciting benefits of CL tools. We investigated how CL and perceived enjoyment (PE) may motivate individuals' SM adoption and how users' technology-related beliefs, specifically perceived ease of use (PEU) and perceived usefulness (PU) of SM, may intervene in the relationship between these factors. The target population was narrowed down to the Pakistani public university student community. Based on the technology acceptance model (TAM) by Davis (1989) and constructivism theory (CT) by Vygotsky (1978), this study contributes to the literature by conceptualizing and empirically testing a student SM adoption model. 


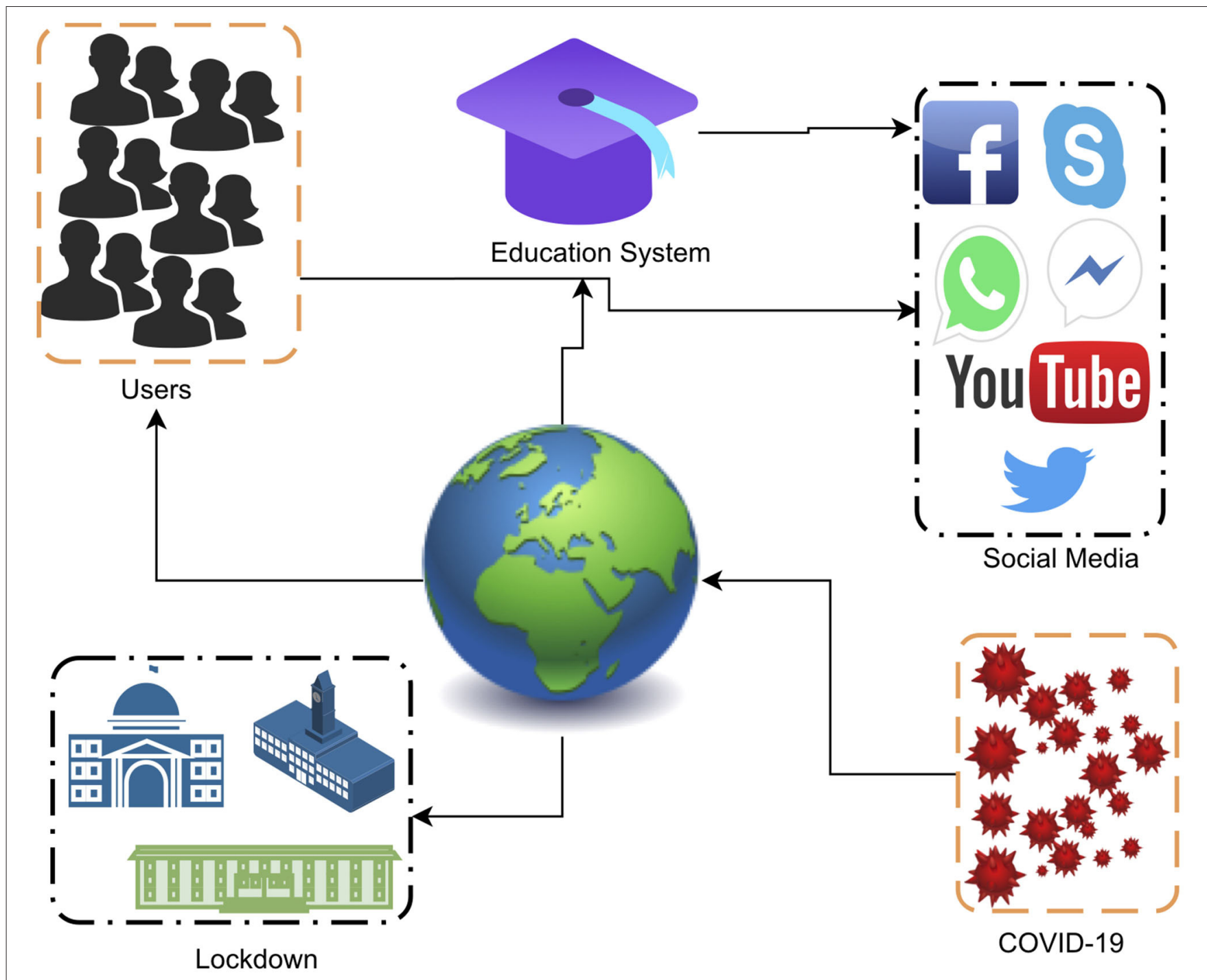

FIGURE 1 | Social media adoption during the COVID-19 pandemic.

\section{LITERATURE REVIEW}

\section{Social Media for Learning}

COVID-19 was first identified on December 8, 2019, in Wuhan (Hubei Province, China) (Khan et al., 2020). First, it began to spread in China and soon spread globally. UNESCO reported that the closure of academic institutes caused by the pandemic has affected 890 million students in 114 countries. Online learning has become a new routine for some students; however, it has brought huge challenges. According to Almaiah et al. (2020) online learning does not only involve infrastructure issues but also some other issues such as online learning system technical issues, change management issues, course design issues, computer self-efficacy, and financial support issues. Given the social inequalities in many countries, not all students have access to this kind of education (UNESCO, 2020). More than
144 countries closed academic institutions, affecting more than $67.7 \%$ of students worldwide. Some other countries closed academic institutions at the regional level, and if these closures occur at the national level, millions of other students will suffer disruption in their education (UNESCO, 2020). The social distance phenomenon has led to many rapid changes in the higher education landscape. Historically, the collective student community has never suddenly shifted from face-toface instruction to distant instruction using digital technologies. Academic institutions have been compelled to adopt new ways to keep operating and maintain communication using digital technology, and to entirely restructure their education models in responding to pandemic-specific demand criteria. Digital technologies are increasingly used in business and educational sectors, and, on a societal level, increased digital technology use enables people worldwide to keep in touch (Dwivedi et al., 2020). 
In the educational context, the adoption level of emerging web technologies is rapidly increasing. The extensive popularity of SM in education makes it essential for teachers and students to understand and adopt SM sites to establish future educational strategies and deploy present course materials on emerging technology-powered platforms (Sarwar et al., 2019; Bai et al., 2021). The use of the Internet for social networking is prevalent among youth. Collaborative technology contributes to an online community that can interact rapidly and easily. SM adoption in education has been investigated in several contexts. However, in the context of higher education only one study, which was a small-scale study, has closely observed students' adoption of SM for e-learning (Gunasagaran et al., 2019). During a pandemic, higher education institutions can use e-learning systems to help manage, plan, deliver, and track students' academic learning and faculty teaching activities (Almaiah et al., 2020). Furthermore, SM promote collaboration and participation among students and improve their learning performance (Al-Rahmi et al., 2020). Increased SM assimilation and use has become an important prerequisite for different learning applications and other related resources. Such aspects are considered useful because SM tools work through Internet-based mechanisms to disseminate and exchange information and create an environment for collaboration (Esam and Hashim, 2016).

Besides, the unprecedented rise of mobile technology in recent years has positively impacted the interaction and collaboration between teachers and students. SM provide unique features, such as CL, open-loop feedback, and two-way communication. These features enable many people to easily share their ideas, opinions, experiences, prospects, information, and knowledge freely via SM (Rau et al., 2008; Al-Rahmi et al., 2018). Moreover, SM usage enhances students' communication skills, and this means of communication enables them to collaborate and communicate despite geographical constraints, boosting their learning performance (Williams et al., 2012; Qi, 2019; Berkani, 2020) and encouraging them to work in groups; thus, members help each other by correcting each other's errors, improving their learning progress or performance (Paul et al., 2005). SM provides a platform for students and teachers to discuss their concepts and examine them with their peers (Tess, 2013). It is also a suitable way for students to easily receive feedback from their peers (Rahman et al., 2019). Considering all these advantages, we believe that SM is a valuable educational tool that can be used to enrich learning behavior (Al-Bahrani et al., 2015).

\section{Technology Adoption Models}

Technology acceptance among its users is vital to ensuring the success of the system's implementation. Hence, it is important to understand and identify the factors that affect students' acceptance of SM learning. Scholars have presented several theories to determine the important factors that contribute to the acceptance of technology and SM in teaching and learning. Among these theories, the TAM, developed by Davis (1989), has been widely used in studies aiming to determine the factors affecting users' acceptance of new technology (Almaiah et al., 2016). The TAM model focuses on two primary factors, namely PEU and PU, which influence individuals' intention to use new technology. According to the TAM model, external variables influence individuals' internal beliefs, and the sequential relationship between individuals' personal beliefs, attitudes, and behavioral intentions leads them to use the actual system, which, in turn, helps researchers predict the acceptance of technology by its users. Many studies have used the TAM to explore the acceptance of technology among students in its original form (Davis, 1989), while others have used the extended model (Almaiah et al., 2016).

In addition to the TAM, other theories such as the Theory of Reasoned Action (TRA), the Innovation Diffusion Theory (IDT), DeLone and McLean's Information System Success Model (DL\&ML model), and the Unified Theory of Acceptance and Use of Technology (UTAUT) are also used to investigate dominant determinants of accepting technology in learning environments. The TRA, developed by Fishbein and Ajzen (1975), suggests that individuals' behavior is determined by their intention to perform the behavior. This theory holds that one's intention to engage in a specific behavior is the best predictor of his/her engagement in that behavior. Regarding the IDT, Rogers proposed a diffusion process in which innovation is transferred and adopted within certain social systems over time, involving four basic elements: innovation, communication channel, time, and the social system. This diffusion results in the adoption of new ideas and behaviors among individuals who are part of the social system. However, for adoption to occur, individuals must perceive the behavior as new or innovative. The DL\&ML model, developed by DeLone and McLean (2003), offers a broad assessment of the extent of information system success, which involves six components of which three, namely, service quality, system quality, and information quality, affect user satisfaction and intention to use, which, in turn, result in net benefits. Aside from these models, Venkatesh et al. (2003) proposed the UTAUT model by combining usage models to explain individuals' acceptance of an information technology and intention to use the same.

All these models and theories have been used, modified, and confirmed by prior research examining technology acceptance. Almaiah et al. (2016) employed the TAM model in the Jordanian context to examine students' acceptance of smart technology in learning. This study found that external quality factors positively affect students' adoption of new technology. Almaiah and Alismaiel (2018) combined the TAM with the DL\&ML model to examine the effect of quality factors on the acceptance of mobile learning applications and found that the content, service, and quality of the system encourage students to use learning applications. Al-Shihi et al. (2018) combined the TAM and UTAUT models to explore the determinants of mobile learning acceptance in Oman. Cheng (2012) conducted a study in Taiwan to determine the factors influencing mobile learning acceptance by combining the TAM with the IDT. Similarly, Alamri et al. (2020) employed the TAM to explore the impact of SM applications on students' achievements in education sustainability in higher education. Collectively, these cited studies suggest that the TAM is a valuable and beneficial framework for explaining the use of technology and the Internet in educational settings. 


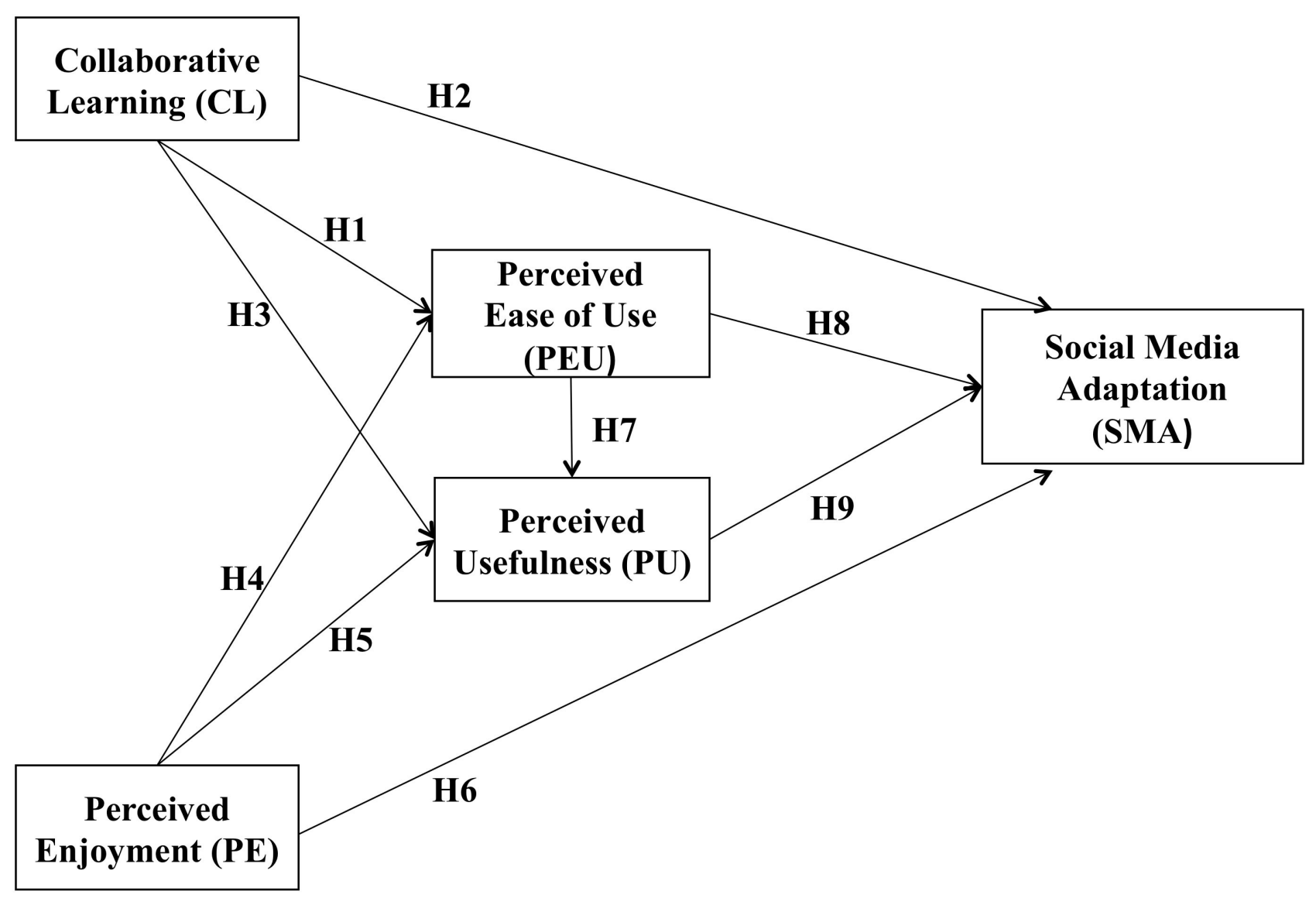

FIGURE 2 | Conceptual model based on TAM and CT.

\section{THEORETICAL BACKGROUND AND HYPOTHESES}

In this study, we developed a theoretical framework by merging two theories, TAM and CT. Davis designed the TAM to establish the causal relationship between the internal views, perspective, and users' intentions to adopt computer technology (Davis, 1989). Researchers have widely used the TAM to study computer technology and information systems. For example, Alamri et al. (2020) used the TAM to examine the impact of SM applications on students' achievement in higher education in Saudi Arabia. They combined the key aspects of the constructivist learning approach with TAM to find that SM applications positively affect students' satisfaction and academic performance. Chandra applied TAM to investigate users' adoption of online auctions (Chandra, 2015). Moreover, CT purports that learning is a continuous and life-long process, resulting from acting in situations (Brown et al., 1989). Students learn by collaborating and working together as peers, applying their comprehensive knowledge to solve problems (Tam, 2000). From a constructivist perspective, learning is mutually constructed through cooperation and communication with others. In the same way, based on CT activities, people acquire knowledge through communication with peers (Golub, 1988). Figure 2 shows the conceptual model used in this study.

\section{Collaborative Learning}

CL refers to how students interact via SM with peers, colleagues, friends, and teachers to communicate for CL purposes. The means of communication and CL environments have changed due to SM platforms. CL is considered an important instructional technique to overcome the communication gap among students (Bernard and Rubalcava, 2000). Students who engage in common interests, including socializing with each other, tend to use different SM sites (Arteaga Sánchez et al., 2014; Sobaih et al., 2016). SM also plays an important role in community development, enhancing collaboration, and communication between community members (Arteaga Sánchez et al., 2014). Prior studies demonstrate that SM sites are useful for university and college students for educational purposes (Forkosh-Baruch and Hershkovitz, 2012). Group interaction is positively influenced by CL via SM and participating in social networking, where individuals gain diverse skills through engagement and improved performance (Mazer et al., 2007; Liu et al., 2011; Ku et al., 2013). SM significantly influence students' academic performance, and it is believed that Facebook is suitable for interacting with classmates and teachers (Cao and Hong, 2011; Lin et al., 2019). In terms of education, the utilization of SM promotes CL among students (Liao et al., 2015; Alamri et al., 2020). In particular, many researchers have emphasized the significance of CL and highlighted its potential 
for enhancing academic performance and empowerment. This is possible if students' needs and their formative assessment are prioritized, and a community classroom is created that promotes student participation, improves their academic performance, and manages the exchange of knowledge among them. From this perspective, SM is highly useful for creating academic groups to improve students' academic performance (Pulido et al., 2020). SM enhances students' learning activities and promotes group communication, so their utilization as learning and teaching tools by educational institutions should be encouraged (Merle and Freberg, 2016). Moreover, social networks enable teachers to deliver information, interact with students, and offer students various teaching methods, encouraging them to become active students (Merle and Freberg, 2016). Sugimoto et al. (2015) argue that these enriched learning experiences also help increase students' participation in the classroom. Utilizing social networking sites in education has not only enhanced the learning process itself, but has also enhanced students' psychological health, social interaction, and skills. Universities and higher education institutions should focus on delivering awareness sessions as a way to encourage students and faculty to use mobile SM apps to maximize learning outcomes (Almaiah et al., 2020). Because of their inherent utility and ease of use, students often utilize information and communications technologies, particularly SM, to better collaborate with peers (Wang, 2010; Koh and Lim, 2012). Based on the above discussion, the following hypotheses were developed:

H1: CL is positively related to PEU.

H2: CL is positively related to SM adoption.

H3: CL is positively related to PU.

\section{Perceived Enjoyment}

$\mathrm{PE}$ refers to the degree to which an information technology system serves as an antecedent of perceived user-friendliness and PU. Our study proposes that enjoying technology, specifically enjoying $\mathrm{SM}$, is conducive to the perception of PEU and is perceived as useful for CL. PE pertains to the intrinsic motivation or the affective element that affects the PEU and user acceptance constructs of the TAM (Van der Heijden et al., 2003; Venkatesh and Bala, 2008). PE is defined as the degree to which the service provided by the learning management systems is considered to be enjoyable per se, excluding any performance concern regarding the use of the system (Venkatesh, 2000; Van der Heijden, 2004). Scholars have reported adopting new technologies as performance-enhancing devices and pleasure sources (Venkatesh, 2000; Koenig-Lewis et al., 2015). Furthermore, Van der Heijden (2004) and Agarwal and Karahanna (2000) suggest that PE can be a precursor to PEU and PU, showing that pleasant technology is also considered easier to use and more useful. Based on the above literature, we proposed the following hypotheses:

H4: PE is positively related to PEU.

H5: PE is positively related to PU.

H6: PE is positively related to SM adoption.

\section{Perceived Ease of Use and Usefulness}

PEU refers to the degree to which a user believes that using a specific information technology system will be simple and comparatively free of physical or mental effort (Davis, 1989). In the context of SM, PEU refers to the degree to which SM sites are easy to use (Carlos Martins Rodrigues Pinho and Soares, 2011; Rauniar et al., 2014). PEU and PU are reliable predictors of the adoption rate of different information technologies, such as mobile learning and Internet-based learning systems (Saadé and Bahli, 2005; Althunibat, 2015). Bhattacherjee (2001) stated that PU is the user's perception of the benefits of using a technology system, while Davis (1989) explains PU as subjective, optimistic ideas about the potential benefits of a certain technology system that arise after its use. This research expands on these definitions by defining $\mathrm{PU}$ as a positive subjective notion held by users that the adoption of SM would enhance CL. Based on the above discussion, the following hypotheses were proposed:

H7: PEU is positively related to PU.

H8: PEU is positively related to SM adoption.

H9: PU is positively related SM adoption.

\section{MATERIALS AND METHODS}

We decided to study the driving factors behind SM adoption of by public university students in Pakistan who experienced interruption in regular CL processes during the COVID-19 period from July to August.

\section{Measurement Development}

Due to geographical constraints, for faster distribution, and to minimize the issue of invalid or missing data, an online survey method was used to collect primary data from those who were expected to display excessive SM usage patterns (Luo and Chea, 2020) and who widely adopt SM (Arshad and Akram, 2018). To research SM adoption, five constructs are measured using a five-point Likert scale ranging from 1 (Strongly Agree) to 5 (Strongly Disagree). These constructs include PU, PEU (Alenazy et al., 2019), CL, PE (Sarwar et al., 2019), and SM adoption (AlRahmi et al., 2018). We developed a questionnaire in English to collect corresponding data. All participants signed a consent letter to participate in the study voluntarily. At the beginning of the survey, respondents were also provided with a concise overview of the aim of the research to increase their basic understanding. Respondents were also ensured that the data would only be used for educational purposes, so they were not asked to provide other information. A pilot study (pilot test) with 23 respondents who used SM for more than $2 \mathrm{~h}$ a day revealed a Cronbach's alpha value of 0.7 for each construct, providing an appropriate statistical basis for further in-depth research. Subsequently, revisions based on the feedback obtained were implemented, resulting in the formal survey.

The validity of any inference derived from data relies on the use of appropriate measurement methods. Consistent with previous literature on explanatory and confirmatory 
TABLE 1 | Respondents' demographics.

\begin{tabular}{llc}
\hline Demographics & Criteria & Percentage \\
\hline Gender & Male & 59.5 \\
& Female & 40.4 \\
& Bachelor's (Hons) & 29.4 \\
Qualification & Master's & 42.2 \\
& M.Phil. & 18.3 \\
Usage of social media per day & Ph.D. & 10.0 \\
& 2-3h & 14.8 \\
& 3-4h & 30.7 \\
& 5 or more than 5h & 54.3 \\
\hline
\end{tabular}

research (Henseler et al., 2016), a structural equation modeling (SEM) approach, partial least squares (PLS), was selected as the core measurement method. PLS produces exemplary consistent estimations of a composite model (Benitez et al., 2020) and has been found to have improved accuracy over covariance-based SEM (van Riel et al., 2017). Additionally, PLS enables us to circumvent the necessity of variables to follow a multivariate normal distribution (Chin et al., 2003) by performing component-based SEM. After the primary data collection, it is necessary to assess the common method bias to ensure that there is no systemic bias affecting the collected data (Podsakoff et al., 2003; Valaei et al., 2017).

\section{Formal Survey}

The revised questionnaire was distributed via email, Facebook, WhatsApp, and WeChat over a period of 27 days. To prevent bias, no personal data other than gender and age were obtained. The tools used to conduct the analysis were Jamovi software, for demographic analysis, and SmartPLS 3 software for data analysis of our conceptual model.

\section{Sample Characteristics and Descriptive Statistics}

The demographic characteristics of the participants are presented in Table 1. A total of 325 responses were obtained, 289 of which were deemed valid. Of these, 172 respondents were male, and 117 were female. Validity was defined as abiding by two parameters: (1) a complete observation, and (2) participants reporting a minimum use of SM of $2 \mathrm{~h}$ per day.

\section{Common Method Variance}

We performed a Harman single factor test to assess the potential existence of common method variance (CMV) in our data (Podsakoff et al., 2012). The results revealed that the first-factor value was $38.3 \%$, which was lower than the threshold value of $50 \%$. As such, we concluded that there was no common method bias in the data, and no CMV issue existed in the data. Second, the common latent factor approach suggested by Podsakoff et al. (2012) was also employed. As per this approach, standard regression weights were first computed using a confirmatory factor analysis. Confirmatory factor analysis was then conducted by including a common latent factor in the research model. The
TABLE 2 | Construct validity.

\begin{tabular}{|c|c|c|c|c|c|c|}
\hline Constructs & Items & $\begin{array}{l}\text { Loading } \\
\text { Values }\end{array}$ & Cronbach's a & rho_A & CR & AVE \\
\hline \multirow[t]{4}{*}{ Collaborative learning } & CL1 & 0.873 & 0.883 & 0.885 & 0.919 & 0.740 \\
\hline & CL2 & 0.855 & & & & \\
\hline & CL3 & 0.880 & & & & \\
\hline & CL4 & 0.832 & & & & \\
\hline \multirow[t]{3}{*}{ Perceived enjoyment } & PE1 & 0.863 & 0.797 & 0.814 & 0.880 & 0.709 \\
\hline & PE2 & 0.845 & & & & \\
\hline & PE3 & 0.818 & & & & \\
\hline \multirow[t]{4}{*}{ Perceived ease of use } & PEU1 & 0.732 & 0.772 & 0.885 & 0.839 & 0.567 \\
\hline & PEU2 & 0.821 & & & & \\
\hline & PEU3 & 0.706 & & & & \\
\hline & PEU4 & 0.750 & & & & \\
\hline \multirow[t]{4}{*}{ Perceived usefulness } & PU1 & 0.812 & 0.810 & 0.880 & 0.867 & 0.620 \\
\hline & PU2 & 0.761 & & & & \\
\hline & PU3 & 0.804 & & & & \\
\hline & PU4 & 0.773 & & & & \\
\hline \multirow[t]{3}{*}{ Social media adoption } & SMA1 & 0.864 & 0.853 & 0.853 & 0.911 & 0.772 \\
\hline & SMA2 & 0.879 & & & & \\
\hline & SMA3 & 0.893 & & & & \\
\hline
\end{tabular}

comparison of the regression weights of both analyses revealed no dominant factor emerging from the results, meaning that the common method bias was not an issue in this study.

\section{RESEARCH ANALYSIS}

For this study, we performed SEM analysis to determine the consistency of the measuring tool and to compare it with the study hypotheses, we used SmartPLS 3.0 and applied the PLS method (Molinillo et al., 2018). PLS-SEM is suitable for studying technology acceptance that stresses predictive modeling (Venkatesh and Davis, 2000; Venkatesh and Bala, 2008). The results of this study are divided into two parts: the first part describes the measurement model and reports checks of the consistency between the endogenous and exogenous variables by identifying the composite reliability (CR), convergent validity $(\mathrm{CV})$, Cronbach's alpha (CA), average variance extracted (AVE), factor loadings, and rho_A. The second part discusses our structural model and evaluation of the study hypotheses.

\section{Measurement Model}

The reliability and validity results of our measurement model are listed in Table 2. The CR values of all constructs in our measurement model were $>0.60$, as recommended by Hair et al. (2017). The AVE value of each construct should be larger than the suggested threshold of 0.50 (Fornell and Larcker, 1981), and we observed it to be as so. Furthermore, our study's results indicated that all constructs' CA values were above the recommended value of 0.70 (Fornell and Larcker, 1981; Kannan and Tan, 2005; Lee et al., 2005; Wu et al., 2007).

As an alternative metric for measuring reliability, Dijkstra and Henseler (2015) proposed the rho_A. Our study results of all 
TABLE 3 | Discriminant validity.

\begin{tabular}{|c|c|c|c|c|c|c|c|c|c|c|c|}
\hline \multicolumn{6}{|c|}{ Fornell-Larcker criterion } & \multicolumn{6}{|c|}{ Heterotrait-monotrait ratio (HTMT) } \\
\hline Constructs & CL & PE & PEU & PU & SMA & Constructs & CL & PE & PEU & PU & SMA \\
\hline $\mathrm{CL}$ & 0.860 & & & & & $\mathrm{CL}$ & & & & & \\
\hline $\mathrm{PE}$ & 0.278 & 0.842 & & & & $\mathrm{PE}$ & 0.329 & & & & \\
\hline PEU & 0.415 & 0.489 & 0.753 & & & PEU & 0.430 & 0.551 & & & \\
\hline PU & 0.431 & 0.428 & 0.616 & 0.788 & & PU & 0.453 & 0.469 & 0.641 & & \\
\hline SMA & 0.538 & 0.486 & 0.707 & 0.765 & 0.879 & SMA & 0.619 & 0.580 & 0.730 & 0.827 & \\
\hline
\end{tabular}

Square root of the AVE in bold in the main diagonal.

constructs using Dijkstra-Henseler's rho_A were all above the threshold value of 0.70 , indicating construct reliability. Table 3 indicates the discriminant validity (DV) results based on the Fornell-Larcker criterion.

As shown in bold, the values of the square root of the AVE on the diagonals are greater than the correlations among the constructs. This shows that the constructs are strongly related to their respective indicators compared to other models (Fornell and Larcker, 1981), indicating better DV (Hair et al., 2016). Furthermore, as an alternative, Dijkstra and Henseler proposed the heterotrait-monotrait ratio of correlations (HTMT), where values smaller than 0.85 or 0.90 reliably distinguish latent variable validity (Dijkstra and Henseler, 2015). In our study, all values met significant thresholds, as shown in Table 3. In summary, the measurement model showed appropriate reliability, CV, and DV in our conceptual model.

\section{Structural Model Assessment}

Previous literature suggests assessing the structural model by looking at the beta value ( $\beta$-value), the $R^{2}$-value, and the corresponding $t$ values obtained via a bootstrapping procedure with 5,000 resamples (Hair et al., 2016). Furthermore, it is recommended to report the effect sizes $\left(\mathrm{f}^{2}\right)$ and predictive relevance $\left(Q^{2}\right)$, the results of which are shown in Table 4. $f^{2}>$ $0,0.15$, and 0.35 indicate a small, medium, and large effect size, respectively, and $Q^{2}>0,0.25$, and 0.50 indicate small, medium, and large predictive relevance, respectively (Hair et al., 2019).

As Sullivan and Feinn (2012) argue, the $p$-value determines whether the effect exists, but it does not reveal the size of the effect. The collinearity values were evaluated by producing the variance inflation factor (VIF). VIF values higher than 5 indicate collinearity. The recovered VIF values were entirely within acceptable range values, that is, $<5$ (Mason and Perreault, 1991; Becker et al., 2014), as shown in Table 5.

From the results, we conclude that collinearity did not exist in our data. The results of the structural model assessment are shown in Figure 3 and Table 6. Our study hypothesis results showed that CL $(\beta=0.302, t=5.838, p<0.001)$ and $\mathrm{PE}(\beta$ $=0.405, t=7.953, p<0.001)$ had a significant relationship with PEU. This result supports $\mathrm{H} 3$ and H5. Additionally, CL was found to be significantly associated with SM adoption $(\beta=0.191$, $t=5.293, p<0.001$ ), which also provides grounds for accepting H6. Moreover, PEU and PU ( $\beta=0.462, t=8.915, p<0.001)$ were positively and significantly associated. Finally, the $\mathrm{H} 8$ ( $\beta=$
TABLE 4 | Standard assessment criteria of a structure model.

\begin{tabular}{|c|c|c|c|c|c|c|}
\hline Constructs & & $f^{2}$ & & $R^{2}$ & $R^{2}$ Adjusted & $Q^{2}$ \\
\hline $\mathrm{CL}$ & 0.125 & 0.057 & 0.097 & & & \\
\hline $\mathrm{PE}$ & 0.224 & 0.028 & 0.020 & & & \\
\hline PEU & & 0.255 & 0.168 & 0.323 & 0.319 & 0.152 \\
\hline $\mathrm{PU}$ & & & 0.413 & 0.433 & 0.427 & 0.234 \\
\hline SMA & & & & 0.710 & 0.706 & 0.542 \\
\hline
\end{tabular}

TABLE 5 | Standard assessment criteria of a structure model.

\begin{tabular}{lc}
\hline Constructs & VIF \\
\hline CL1 & 2.683 \\
CL2 & 2.479 \\
CL3 & 2.447 \\
CL4 & 1.966 \\
PE1 & 1.636 \\
PE2 & 1.854 \\
PE3 & 1.662 \\
PEU1 & 1.678 \\
PEU2 & 1.236 \\
PEU3 & 1.674 \\
PEU4 & 1.729 \\
PU1 & 1.344 \\
PU2 & 2.059 \\
PU3 & 1.850 \\
PU4 & 2.046 \\
SMA1 & 1.898 \\
SMA2 & 2.191 \\
SMA3 & 2.339 \\
\hline
\end{tabular}

0.301, $t=7.861, p<0.001)$ and $\mathrm{H} 9(\beta=0.460, t 13.595, p<$ $0.001)$ results revealed that the relationship of PEU and PU with SM adoption was positive and significant. Overall, the results supported all hypotheses.

\section{DISCUSSION}

From its onset until December 31, 2020, over 81 million new COVID-19 cases were reported by the World Health Organization (2021). The ongoing COVID-19 pandemic has 


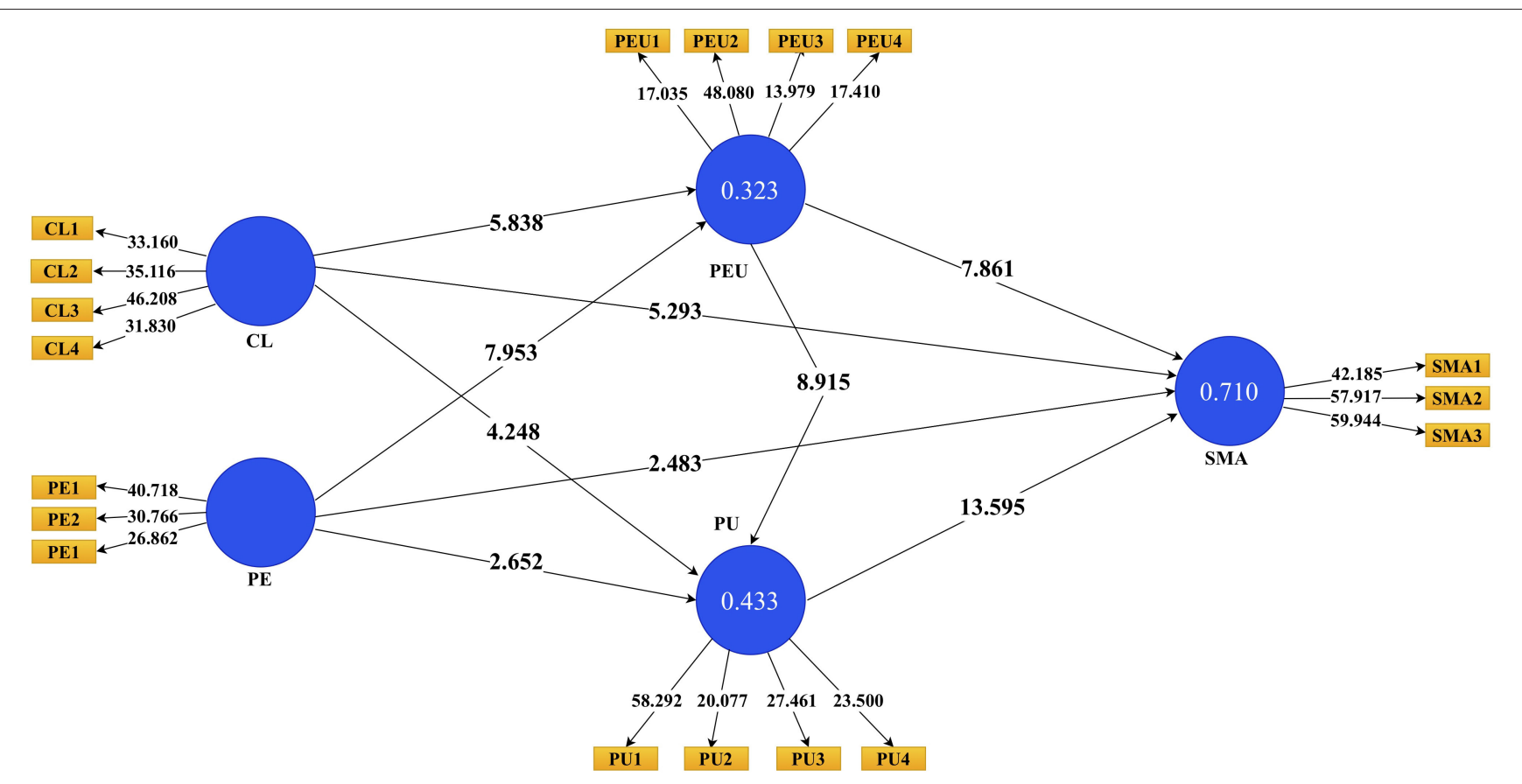

FIGURE 3 | Bootstrapping path coefficient results.

TABLE 6 | Path coefficient results.

\begin{tabular}{llllllll}
\hline No & & OS (O) & $\boldsymbol{M}$ & SD & $\boldsymbol{T}$-Value & $\boldsymbol{P}$-Values & Result \\
\hline 1 & CL -> PEU & 0.302 & 0.303 & 0.052 & 5.838 & 0.000 & Accepted \\
2 & CL -> SMA & 0.191 & 0.191 & 0.036 & 5.293 & 0.000 & Accepted \\
3 & CL -> PU & 0.199 & 0.201 & 0.047 & 4.248 & 0.000 & Accepted \\
4 & PE -> PEU & 0.405 & 0.407 & 0.051 & 7.953 & 0.000 & Accepted \\
5 & PE -> PU & 0.146 & 0.147 & 0.055 & 2.652 & 0.008 & Accepted \\
6 & PE -> SMA & 0.089 & 0.090 & 0.036 & 2.483 & 0.013 & Accepted \\
7 & PEU -> PU & 0.462 & 0.462 & 0.052 & 8.915 & 0.000 & Accepted \\
8 & PEU -> SMA & 0.301 & 0.303 & 0.038 & 7.861 & 0.000 & Accepted \\
9 & PU -> SMA & 0.460 & 0.456 & 0.034 & 13.595 & 0.000 & Accepted \\
\hline
\end{tabular}

disrupted every facet of life, including healthcare, education, and the economy ( $\mathrm{Li}$ et al., 2020). Educational institutes were shut down, and students globally were confined to staying at home. As yet, it is uncertain when the imposed lockdowns will be lifted. Social distancing has led to increased SM use among students. SM is a convenient way of communication, and it enables students and teachers to connect and practice social distancing more effectively (Vordos et al., 2020).

This study investigates the basic motivation behind the adoption of SM for CL in the student community during COVID-19. To achieve the aim of this study, we proposed a conceptual framework that expands on the TAM and CT. In the present model, we defined an SM feature, CL, as the key variable underlying SM adoption and identified PEU and PU as important contributing variables. For the proposed hypotheses testing, we collected data by surveying students. The results suggest that CL plays a key role in determining the user's verdict to adopt
SM. Moreover, the PEU and PU of SM play a mediating role in the relationship between SM characteristics and adoption. Overall, the study's findings strongly support the adoption of SM for educational purposes. This notion is strengthened by the alignment, which is consistent with results reported in previous studies (Sobaih et al., 2016; Berger, 2017).

Online learning is becoming more mainstream, and discussions are ripe between researchers about the utility of this medium given the breakthroughs in the ease of use of SM for academic communication. In addition, the study is well-placed to strengthen and advance the literature on CL, PE, and its role in SM adoption by students (Mazman and Usluel, 2010; Arteaga Sánchez et al., 2014).

The study results support the notion that the SM feature CL is a predictor of SM adoption by students in Pakistan. This reveals that students considered that SM enables CL, enhancing communication between friends and classmates. Besides, this result is consistent with that of a previous study by Arshad and Akram (2018). Our study also shows that students engage in various SM sites where they discuss their educational issues and collaborate with others, which positively impacts their learning performance. Furthermore, the results imply that SM facilitates students to become more creative and dynamic and enables them to easily collaborate with instructors. The study results are supported by a previous study (Ansari and Khan, 2020).

Our findings demonstrate that CL significantly affects PU, PEU, and SM. Students in higher education who adopt SM tend to consider that this platform is useful for collaborating with others, which is consistent with the CT of learning. This result aligns with that of previous studies by Ebner (2009) and Arshad and Akram (2018), who found that SM sites 
such as blogs are useful for CL between students and tutors. Furthermore, PE has a significant effect on PU, PEU, and SM. This finding demonstrates that the extensive popularity of SM among students is partly due to its ease of use. Students use SM for different purposes, such as enjoyment, knowledge sharing, and CL; this result is consistent with previous literature (Koenig-Lewis et al., 2015; Al-Rahmi et al., 2020). Similarly, our study results indicate that $\mathrm{PU}$ and $\mathrm{PEU}$ also have a positive relationship with SM adoption. SM tools facilitate resource sharing, as learners perceive this medium to be easy to use and useful because it helps them share information with the relevant person more effectively and efficiently. This result echoes previous research (Al-Rahmi et al., 2018; Sarwar et al., 2019). In addition, in this study, PEU was shown to have a significant relationship with $\mathrm{PU}$, which was also reported by Alenazy et al. (2019).

SM can change the conventional educational method and provide a platform for students where they can directly communicate and collaborate with different people globally (Reid and Ostashewski, 2010; Forkosh-Baruch and Hershkovitz, 2012). This point is supported by two theoretical perspectives: the CT and computer-mediated learning (CML). The emphasis of CT on social contact and collaboration lies in the fact that CML eradicates topographical hurdles. Hence, to gain useful learning experiences related to $\mathrm{CL}$, it is imperative to develop social groups to exercise and use CL setting abilities on SM networks.

\section{RESEARCH IMPLICATIONS}

The present study has important implications for students, higher educational institutions, and policymakers. The relationship between the use of SM and its positive impact on students' performance is crucial to understanding the role of SM during a pandemic. The findings are relevant to those interested in enhancing online learning or the SM tools utilized for CL. This study furthers our understanding of why students choose to adopt SM sites during COVID-19. Through a greater comprehension of intention determinants, inclination toward e-learning among students, and useful technology, informed policy decisions can be reached for educational technology implementation in tertiary education institutions. The findings of this study will increase educational administrators' awareness of the benefits of advanced technology, such as SM in academic institutions, and assist them in developing an interesting and suitable online learning environment for the student community. Furthermore, teachers and students should consider SM as an informal learning tool that creates a comfortable environment for CL and social interaction. Educational administrators, policymakers, and teachers can use SM as a complementary learning tool, and students can use it for CL. Further, based on our study results, we suggest that educational institutions develop their own pages and groups on different SM platforms and invite students to join these groups and pages, which may help students tackle educational problems. Students can join groups or pages using official email addresses. Such initiatives may reduce student search effort, a constraint, and thus more efficiently achieve favorable CL with peers regardless of location or time.

\section{LIMITATIONS AND FUTURE WORK}

The present study identified some interesting findings; nevertheless, several limitations exist. Notably, the sample population was limited to public universities in Pakistan. Hence, this study's results may not conclusively reflect private university students' tendency toward SM adoption during COVID-19 in Pakistan. Additionally, this study did not distinguish between specific SM platforms such as Facebook, Instagram, and Twitter. As such, it did not yield detailed platform-specific descriptive statistics for use during COVID-19 for educational purposes or collaboration. Accordingly, future research should be confined to a specific SM platform. Future research should be conducted with faculty members to understand their perspective on SM adoption for CL during the pandemic. Although the model has been tested in Pakistan, future research should replicate or extend the proposed conceptual model in technologically advanced countries with different economic and cultural conditions.

\section{CONCLUSION}

This study advances research on SM adoption by students during COVID-19 for the purpose of CL. This is achieved by proposing and empirically testing a conceptual model based on the TAM and CT. Social media, as a tool, as well as its features, is indispensable and extremely vital for students in higher education. Concurrently, SM may be useful in enhancing learning performance, knowledge sharing, and collaboration among students. Social media provides a learning platform for students where they can easily communicate with their peers, teachers, and subject specialists. Furthermore, the use of SM is conducive to enhancing learners' CL. Particularly in a time of growing focus on expedient delivery of coursework through digital technologies, students, higher educational institutions, and policymakers may ascertain a positive impact on CL through SM adoption by students. The study results indicate that CL, $\mathrm{PE}, \mathrm{PEU}$, and PU are vital contributors of SM adoption by students in higher education. With an extended understanding of the determinants of SM adoption motivation and inclination toward e-learning between students who experience constraints during a pandemic, informed policy decisions can be reached. Crucially, however, scope restrictions, in particular, the small sample of the study, comprising 289 public university students, and the geographic restriction of Pakistan, impede the ability to draw conclusive inferences on the effectiveness of the conceptual model; thus, replicative research in technologically advanced countries with different economic and cultural conditions is warranted.

\section{DATA AVAILABILITY STATEMENT}

The data analyzed in this study is subject to the following licenses/restrictions: data is available on request. 
Requests to access these datasets should be directed to azeem20037@gmail.com.

\section{ETHICS STATEMENT}

The studies involving human participants were reviewed and approved by Hunan University, Nanjing University. The patients/participants provided their written informed consent to participate in this study.

\section{AUTHOR CONTRIBUTIONS}

MNK and MAA: conceptualization and formal analysis. MNK and DS: methodology. MNK: software. MNK, MAA, and DS: resources and writing-original draft preparation. MNK, MAA,

\section{REFERENCES}

Abi-Rafeh, J., and Azzi, A. J. (2020). Emerging role of online virtual teaching resources for medical student education in plastic surgery: covid19 pandemic and beyond. J. Plast. Reconstr. Aesthet. Surg. 73, 1575-1592. doi: 10.1016/j.bjps.2020.05.085

Abi-Rafeh, J., El-Hawary, H., and Azzi, A. J. (2019). PRS medical student corner: the value of collaboration and mentorship in plastic surgery. Plast. Reconstr. Surg. Glob. Open 7:e2319. doi: 10.1097/gox.0000000000002319

Adnan, M. (2020). Online learning amid the Covid-19 pandemic: students perspectives. J. Pedagogical Sociol. Psychol. 1, 45-51. doi: $10.33902 /$ jpsp. 2020261309

Agarwal, R., and Karahanna, E. (2000). Time flies when you're having fun: cognitive absorption and beliefs about information technology usage. MIS Q. 24:665. doi: 10.2307/3250951

Alamri, M. M., Almaiah, M. A., and Al-Rahmi, W. M. (2020). Social media applications affecting students' academic performance: a model developed for sustainability in higher education. Sustainability 12:6471. doi: 10.3390/su12166471

Al-Bahrani, A., Patel, D., and Sheridan, B. (2015). Engaging students using social media: the students' perspective. Int. Rev. Econ. Educ. 19, 36-50. doi: 10.1016/j.iree.2015.06.001

Alenazy, W. M., Mugahed Al-Rahmi, W., and Khan, M. S. (2019). Validation of tam model on social media use for collaborative learning to enhance collaborative authoring. IEEE Access 7, 71550-71562. doi: 10.1109/access.2019.2920242

Almaiah, M. A., and Alismaiel, O. A. (2018). Examination of factors influencing the use of mobile learning system: an empirical study. Educ. Inform. Technol. 24, 885-909. doi: 10.1007/s10639-018-9810-7

Almaiah, M. A., Al-Khasawneh, A., and Althunibat, A. (2020). Exploring the critical challenges and factors influencing the e-learning system usage during COVID-19 pandemic. Educ. Inform. Technol. 25, 5261-5280. doi: 10.1007/s10639-020-10219-y

Almaiah, M. A., Jalil, M. A., and Man, M. (2016). Extending the TAM to examine the effects of quality features on mobile learning acceptance. J. Comput. Educ. 3, 453-485. doi: 10.1007/s40692-016-0074-1

Al-Rahmi, W. M., Alias, N., Othman, M. S., Marin, V. I., and Tur, G. (2018). A model of factors affecting learning performance through the use of social media in Malaysian higher education. Comput. Educ. 121, 59-72. doi: 10.1016/j.compedu.2018.02.010

Al-Rahmi, W. M., Yahaya, N., Alturki, U., Alrobai, A., Aldraiweesh, A. A., Omar Alsayed, A., et al. (2020). Social media - based collaborative learning: the effect on learning success with the moderating role of cyberstalking and cyberbullying. Inter. Learn. Environ. doi: 10.1080/10494820.2020.1728342. [Epub ahead of print].
KUK, and RAL: writing-review and editing. All authors have read and agreed to the published version of the manuscript.

\section{FUNDING}

The authors disclose receipt of the following financial support for the research, authorship, and/or publication of this article: this study was funded by the National Natural Science Foundation of China (Grant No.: 71950410624).

\section{ACKNOWLEDGMENTS}

The authors thank all students who showed interest in our study and helped us in the data collection during the COVID19 pandemic.

Al-Shihi, H., Sharma, S. K., and Sarrab, M. (2018). Neural network approach to predict mobile learning acceptance. Educ. Inform. Technol. 23, 1805-1824. doi: 10.1007/s10639-018-9691-9

Althunibat, A. (2015). Determining the factors influencing students' intention to use m-learning in Jordan higher education. Comput. Hum. Behav. 52, 65-71. doi: 10.1016/j.chb.2015.05.046

Ansari, J. A., and Khan, N. A. (2020). Exploring the role of social media in collaborative learning the new domain of learning. Smart Learn. Environ. 7:9. doi: 10.1186/s40561-020-00118-7

Arshad, M., and Akram, M. S. (2018). Social media adoption by the academic community: theoretical insights and empirical evidence from developing countries. Int. Rev. Res. Open Distrib. Learn. 19, 243-262. doi: 10.19173/irrodl.v19i3.3500

Arteaga Sánchez, R., Cortijo, V., and Javed, U. (2014). Students' perceptions of Facebook for academic purposes. Comput. Educ. 70, 138-149. doi: 10.1016/j.compedu.2013.08.012

Bai, J., Mo, K., Peng, Y., Hao, W., Qu, Y., Lei, X., et al. (2021). The relationship between the use of mobile social media and subjective wellbeing: the mediating effect of boredom proneness. Front. Psychol. 11:568492. doi: 10.3389/fpsyg.2020.568492

Becker, J., Ringle, C. M., Sarstedt, M., and Völckner, F. (2014). How collinearity affects mixture regression results. Mark. Lett. 26, 643-659. doi: 10.1007/s11002-014-9299-9

Benitez, J., Henseler, J., Castillo, A., and Schuberth, F. (2020). How to perform and report an impactful analysis using partial least squares: guidelines for confirmatory and explanatory is research. Inform. Manag. 57:103168. doi: 10.1016/j.im.2019. 05.003

Berger, P. (2017). Beyond plain acceptance or sheer resistance: a typology of university instructors' attitudes to students' media use in class. Teach. Teach. Educ. 67, 410-417. doi: 10.1016/j.tate.2017. 07.009

Berkani, L. (2020). A semantic and social-based collaborative recommendation of friends in social networks. Software Pract. Exper. 50, 1498-1519. doi: $10.1002 /$ spe. 2828

Bernard, R. M., and Rubalcava, B. R. (2000). Collaborative online distance learning: issues for future practice and research. Dis. Educ. 21, 260-277. doi: 10.1080/0158791000210205

Bhattacherjee, A. (2001). Understanding information systems continuance: an expectation-confirmation model. MIS Q. 25:351. doi: 10.2307/3250921

Brown, J. S., Collins, A., and Duguid, P. (1989). Situated cognition and the culture of learning. Educ. Res. 18, 32-42. doi: 10.3102/0013189X018001032

Cao, Y., and Hong, P. (2011). Antecedents and consequences of social media utilization in college teaching: a proposed model with mixed-methods investigation. Horizon 19, 297-306. doi: 10.1108/10748121111179420 
Carlos Martins Rodrigues Pinho, J., and Soares, A. M. (2011). Examining the technology acceptance model in the adoption of social networks. J. Res. Inter. Mark. 5, 116-129. doi: 10.1108/17505931111187767

Chan, A. K., Nickson, C. P., Rudolph, J. W., Lee, A., and Joynt, G. M. (2020). Social media for rapid knowledge dissemination: early experience from the covid-19 pandemic. Anaesthesia 75, 1579-1582. doi: 10.1111/anae.15057

Chandra, C. P. (2015). The adoption of E-auction in Indonesia: the extended technology acceptance model study. iBuss Manag. 3, 423-433.Available online at: http://publication.petra.ac.id/index.php/ibm/article/view/3770

Cheng, Y. M. (2012). Effects of quality antecedents on e-learning acceptance. Inter. Res. 22, 361-390. doi: 10.1108/10662241211235699

Chin, W. W., Marcolin, B. L., and Newsted, P. R. (2003). A partial least squares latent variable modeling approach for measuring interaction effects: results from a monte carlo simulation study and an electronic-mail emotion/adoption study. Inform. Syst. Res. 14, 189-217. doi: 10.1287/isre.14.2.189. 16018

Davis, F. D. (1989). Perceived usefulness, perceived ease of use, and user acceptance of information technology. MIS Q. 13, 319-340. doi: 10.2307/249008

DeLone, W. H., and McLean, E. R. (2003). The DeLone and McLean model of information systems success: a ten-year update. J. Manag. Inform. Syst. 19, 9-30. doi: 10.1080/07421222.2003.11045748

Dijkstra, T. K., and Henseler, J. (2015). Consistent partial least squares path modeling. MIS Q. 39, 297-316. doi: 10.25300/misq/2015/39.2.02

Dwivedi, Y. K., Hughes, D. L., Coombs, C., Constantiou, I., Duan, Y., Edwards, J. S., et al. (2020). Impact of covid-19 pandemic on information management research and practice: transforming education, work and life. Int. J. Inform. Manag. 55:102211. doi: 10.1016/j.ijinfomgt.2020. 102211

Ebner, M. (2009). Introducing live microblogging: how single presentations can be enhanced by the mass. J. Res. Innov. Teach. 2, 91-100. Available online at: https://www.nu.edu/wp-content/uploads/2018/11/7638_JournalofResearch09. pdf\#page $=96$

Esam, N. M., and Hashim, N. (2016). The impact of social media use on academic performance among UITM Puncak Perdana students. Res. Hub 2, 16-23. Available online at: https://researchhub.uitm.edu.my/pdf/Hidayah1.pdf

Fishbein, M., and Ajzen, I. (1975). Belief, Attitude, Intention and Behavior: An Introduction to Theory and Research. Reading, MA: Addison-Wesley.

Forkosh-Baruch, A., and Hershkovitz, A. (2012). A case study of Israeli highereducation institutes sharing scholarly information with the community via social networks. Inter. High. Educ. 15, 58-68. doi: 10.1016/j.iheduc.2011. 08.003

Fornell, C., and Larcker, D. F. (1981). Evaluating structural equation models with unobservable variables and measurement error. J. Mark. Res. 18, 39-50. doi: $10.2307 / 3151312$

Golub, J. (1988). Focus on Collaborative Learning. Classroom Practices in Teaching English. Urbana, IL: National Council of Teachers of English.

Greenhow, C., and Chapman, A. (2020). Social distancing meet social media: digital tools for connecting students, teachers, and citizens in an emergency. Inform. Learn. Sci. 121, 341-352. doi: 10.1108/ils-042020-0134

Gunasagaran, D. S., Tamilsalvi Mari, D. M., Srirangam, D. S., and Kuppusamy, D. S. (2019). Adoption of social media by architecture students in fostering community SERVICE initiative using technology acceptance model. IOP Conf. Ser. Mater. Sci. Eng. 636:012015. doi: 10.1088/1757-899x/636/1/0 12015

Hair, J., Hollingsworth, C. L., Randolph, A. B., and Chong, A. Y. (2017). An updated and expanded assessment Of PLS-SEM in information systems research. Industr. Manag. Data Syst. 117, 442-458. doi: 10.1108/imds-04-2016-0130

Hair, J. F., Hult, G. T. M., Ringle, C., and Sarstedt, M. (2016). A Primer on Partial Least Squares Structural Equation Modeling (PLS-SEM), 2 nd Edn. London: Sage.

Hair, J. F., Sarstedt, M., and Ringle, C. M. (2019). Rethinking some of the rethinking of partial least squares. Eur. J. Mark. 53, 566-584. doi: 10.1108/ejm-10-2018-0665

Henseler, J., Hubona, G., and Ray, P. A. (2016). "Partial least squares path modeling: updated guidelines," in The Partial Least Squares Path Modeling Basic Concepts, Methodological Issues and Applications, eds H. Latan and R. Noonan (Cham: Springer), 19-39.
Holmes, R. (2020). "Is COVID-19 Social Media's Levelling up Moment?" Available online at: https://www.forbes.com/sites/ryanholmes/2020/04/24/ is-covid-19-social-medias-levelling-up-moment/?sh=7a9be1c86c60 (accessed May 5, 2021).

Islam, A. N., Laato, S., Talukder, S., and Sutinen, E. (2020). Misinformation sharing and social media fatigue during COVID-19: an affordance and cognitive load perspective. Technol. Forecast. Soc. Change 159:120201. doi: 10.1016/j.techfore.2020.120201

Kannan, V. R., and Tan, K. C. (2005). Just in time, total quality management, and supply chain management: understanding their linkages and impact on business performance. Omega 33, 153-162. doi: 10.1016/j.omega.2004.03.012

Karasneh, R., Al-Azzam, S., Muflih, S., Soudah, O., Hawamdeh, S., and Khader, Y. (2021). Media's effect on Shaping knowledge, awareness RISK perceptions and communication practices of pandemic COVID-19 AMONG pharmacists. Res. Soc. Administr. Pharm. 17, 1897-1902. doi: 10.1016/j.sapharm.2020.04.027

Khan, S., Khan, M., Maqsood, K., Hussain, T., Noor-ul-Huda, and Zeeshan, M. (2020). Is Pakistan prepared for THE COVID-19 epidemic? A questionnairebased survey. J. Med. Virol. 92, 824-832. doi: 10.1002/jmv.25814

Khan, T. M. (2020). Use of social media and WhatsApp to conduct teaching activities during the COVID-19 lockdown in Pakistan. Int. J. Pharm. Pract. 29:90. doi: 10.1111/ijpp.12659

Koenig-Lewis, N., Marquet, M., Palmer, A., and Zhao, A. L. (2015). Enjoyment and social influence: predicting mobile payment adoption. Serv. Industr. J. 35, 537-554. doi: 10.1080/02642069.2015.1043278

Koh, E., and Lim, J. (2012). Using online collaboration applications for group assignments: the interplay between design and human characteristics. Comput. Educ. 59, 481-496. doi: 10.1016/j.compedu.2012.02.002

Krishnamurthy, S. (2020). The future of business education: a commentary in the shadow of the Covid-19 pandemic. J. Bus. Res. 117, 1-5. doi: 10.1016/j.jbusres.2020.05.034

$\mathrm{Ku}, \mathrm{H}$., Tseng, H. W., and Akarasriworn, C. (2013). Collaboration factors, teamwork satisfaction, and student attitudes toward online collaborative learning. Comput. Hum. Behav. 29, 922-929. doi: 10.1016/j.chb.2012.12.019

Laato, S., Laine, T. H., and Islam, A. N. (2020). Location-based games and the covid-19 pandemic: an analysis of responses from game developers and players. Multimodal Technol. Inter. 4:29. doi: 10.3390/mti4020029

Lee, M. K., Cheung, C. M., and Chen, Z. (2005). Acceptance of internet-based learning medium: the role of extrinsic and intrinsic motivation. Inform. Manag. 42, 1095-1104. doi: 10.1016/j.im.2003.10.007

Li, C. H., Rajamohan, A. G., Acharya, P. T., Liu, C. S. J., Patel, V., Go, J. L., et al. (2020). Virtual read-out: radiology education for the 21 st century during the COVID-19 pandemic. Acad. Radiol. 27, 872-881. doi: 10.1016/j.acra.2020.04.028

Liao, Y., Huang, Y., Chen, H., and Huang, S. (2015). Exploring the antecedents of collaborative learning performance over social networking sites in a ubiquitous learning context. Comput. Hum. Behav. 43, 313-323. doi: 10.1016/j.chb.2014.10.028

Lin, M., Vijayalakshmi, A., and Laczniak, R. (2019). Toward an understanding of parental views and actions on social media influencers targeted at adolescents: the roles of parents' social media use and empowerment. Front. Psychol. 10:2664. doi: 10.3389/fpsyg.2019.02664

Liu, C. C., Liu, K. P., Chen, W. H., Lin, C. P., and Chen, G. D. (2011). Collaborative storytelling experiences in social media: influence of peer-assistance mechanisms. Comput. Educ. 57, 1544-1556. doi: 10.1016/j.compedu.2011.02.002

Luo, M. M., and Chea, S. (2020). Wiki use for knowledge integration and learning: a three tier conceptualization. Comput. Educ. 154:103920. doi: 10.1016/j.compedu.2020.103920

Madhav, N., Oppenheim, B., Gallivan, M., Mulembakani, P., Rubin, E., and Wolfe, N. (2017). Pandemics: Risks, Impacts, and Mitigation. Disease Control Priorities, 3rd Edn., Vol. 9. Washington, DC: Improving Health and Reducing Poverty Published.

Mason, C. H., and Perreault, W. D. (1991). Collinearity, power, and interpretation of multiple regression analysis. J. Mark. Res. 28, 268-280. doi: 10.2307/3172863

Mazer, J. P., Murphy, R. E., and Simonds, C. J. (2007). I'll see you on "facebook": the effects of computer-mediated teacher self-disclosure on student motivation, affective learning, and classroom climate. Commun. Educ. 56, 1-17. doi: 10.1080/03634520601009710 
Mazman, S. G., and Usluel, Y. K. (2010). Modeling educational usage of Facebook. Comput. Educ. 55, 444-453. doi: 10.1016/j.compedu.2010.02.008

McMurtrie, B. (2020). The coronavirus has pushed courses online. Professors are trying hard to keep up. Chron. High. Educ. 66. Available online at: https:// www.chronicle.com/article/the-coronavirus-has-pushed-courses-onlineprofessors-are-trying-hard-to-keep-up/

Merle, P., and Freberg, K. (2016). All about that tweet: student perceptions of professors' social media use in the classroom. J. Res. Inter. Mark. 10, 124-136. doi: 10.1108/jrim-01-2015-0008

Molinillo, S., Aguilar-Illescas, R., Anaya-Sánchez, R., and Vallespín-Arán, M. (2018). Exploring the impacts of interactions, social presence and emotional engagement on active collaborative learning in a social web-based environment. Comput. Educ. 123, 41-52. doi: 10.1016/j.compedu.2018.04.012

Paul, R., Hiler, W., and Elder, L. (2005). The Miniature Guide to Practical Ways for Promote Active and Cooperative Learning. Tomales, CA: The Foundation for Critical Thinking. Rowman and Littlefield.

Podsakoff, P. M., MacKenzie, S. B., Lee, J.-Y., and Podsakoff, N. P. (2003). Common method biases in behavioral research: a critical review of the literature and recommended remedies. J. Appl. Psychol. 88, 879-903. doi: 10.1037/0021-9010.88.5.879

Podsakoff, P. M., MacKenzie, S. B., and Podsakoff, N. P. (2012). Sources of method bias in social science research and recommendations on how to control it. Ann. Rev. Psychol. 63, 539-569. doi: 10.1146/annurev-psych-120710-100452

Pulido, C. M., Mara, L.-C., Ionescu, V., and Sordé-Martí, T. (2020). Social impact of psychological research on well-being shared in social media. Front. Psychol. 11:135. doi: 10.3389/fpsyg.2020.00135

Qi, C. (2019). Social media usage of students, role of tie strength, and perceived task performance. J. Educ. Comput. Res. 57, 385-416. doi: $10.1177 / 0735633117751604$

Rahman, S., Ramakrishnan, T., and Ngamassi, L. (2019). Impact of social media use on student satisfaction in higher education. High. Educ. Q. 74, 304-319. doi: $10.1111 /$ hequ. 12228

Ramsha, J. (2020). "Social media outlets see surge in number of pakistani users." Dawn. Available online at: https://www.dawn.com/news/1548993 (accessed May 5, 2020).

Rau, P.-L. P., Gao, Q., and Ding, Y. (2008). Relationship between the level of intimacy and lurking in online social network services. Comput. Hum. Behav. 24, 2757-2770. doi: 10.1016/j.chb.2008.04.001

Rauniar, R., Rawski, G., Yang, J., and Johnson, B. (2014). Technology acceptance model (TAM) and social media usage: an empirical study on Facebook. $J$. Enterpr. Inform. Manag. 27, 6-30. doi: 10.1108/jeim-04-2012-0011

Reid, D., and Ostashewski, N. (2010). "Evolution of online teacher professional development in a social networking site: what's been working and what's not," in EdMedia + Innovate Learning, eds J. Herrington and C. Montgomerie (Waynesville, NC: Association for the Advancement of Computing in Education (AACE)), 1117-1122. Available online at: https://www.learntechlib. org/primary/p/34773/

Saadé, R., and Bahli, B. (2005). The impact of cognitive absorption on perceived usefulness and perceived ease of use in on-line learning: an extension of the technology acceptance model. Inform. Manag. 42, 317-327. doi: 10.1016/j.im.2003.12.013

Sarwar, B., Zulfiqar, S., Aziz, S., and Ejaz Chandia, K. (2019). Usage of social media tools for collaborative learning: the effect on learning success with the moderating role of cyberbullying. J. Educ. Comput. Res. 57, 246-279. doi: $10.1177 / 0735633117748415$

Sobaih, A. E., Moustafa, M. A., Ghandforoush, P., and Khan, M. (2016). To use or not to use? Social media in higher education in developing countries. Comput. Hum. Behav. 58, 296-305. doi: 10.1016/j.chb.2016.01.002

Sugimoto, C., Hank, C., Bowman, T., and Pomerantz, J. (2015). Friend or faculty: social networking sites, dual relationships, and context collapse in higher education. First Monday 20. doi: 10.5210/fm.v20i3.5387. Available online at: https://journals.uic.edu/ojs/index.php/fm/article/view/5387

Sullivan, G. M., and Feinn, R. (2012). Using effect size-or why the P value is not enough. J. Graduate Med. Educ. 4, 279-282. doi: 10.4300/jgme-d-12-00156.1
Tam, M. (2000). Constructivism, instructional design, and technology: implications for transforming distance learning. J. Educ. Technol. Soc. 3, 50-60. Available online at: http://www.jstor.org/stable/jeductechsoci.3.2.50

Tess, P. A. (2013). The role of social media in higher education classes (real and virtual) - a literature review. Comput. Hum. Behav. 29, A60-A68. doi: $10.1016 /$ j.chb.2012.12.032

UNESCO (2020). COVID-19 Educational Disruption and Response. Available online at: https://en.unesco.org/themes/education-emergencies/coronavirusschool-closures (accessed May 5, 2021).

Valaei, N., Rezaei, S., and Ismail, W. K. (2017). Examining learning strategies, creativity, and innovation at SMEs using fuzzy set Qualitative Comparative Analysis and PLS path modeling. J. Bus. Res. 70, 224-233. doi: $10.1016 /$ j.jbusres.2016.08.016

Van der Heijden, H. (2004). User acceptance of hedonic information systems. MIS Q. 28, 695-704. doi: 10.2307/25148660

Van der Heijden, H., Verhagen, T., and Creemers, M. (2003). Understanding online purchase intentions: contributions from technology and trust perspectives. Eur. J. Inform. Syst. 12, 41-48. doi: 10.1057/palgrave.ejis.3000445

van Riel, A. C. R., Henseler, J., Kemény, I., and Sasovova, Z. (2017). Estimating hierarchical constructs using consistent partial least squares. Industr. Manag. Data Syst. 117, 459-477. doi: 10.1108/imds-07-2016-0286

Venkatesh, V. (2000). Determinants of perceived ease of use: integrating control, intrinsic motivation, and emotion into the technology acceptance model. Inform. Syst. Res. 11, 342-365. doi: 10.1287/isre.11.4.342.11872

Venkatesh, V. (2020). Impacts of COVID-19: A research agenda to support people in their fight. Int. J. Inform. Manag. 55:102197. doi: 10.1016/j.ijinfomgt.2020.102197

Venkatesh, V., and Bala, H. (2008). Technology acceptance model 3 and a research agenda on interventions. Dec. Sci. 39, 273-315. doi: 10.1111/j.1540-5915.2008.00192.x

Venkatesh, V., and Davis, F. D. (2000). A theoretical extension of the technology acceptance model: four longitudinal field studies. Manag. Sci. 46, 186-204. doi: $10.1287 / \mathrm{mnsc}$.46.2.186.11926

Venkatesh, V., Morris, M., Davis, G., and Davis, F. (2003). User acceptance of information technology: toward a unified view. MIS Q. 27, 425-478. doi: $10.2307 / 30036540$

Vordos, N., Gkika, D. A., Maliaris, G., Tilkeridis, K. E., Antoniou, A., Bandekas, D. V., et al. (2020). How 3D printing and social media tackles the PPE shortage during Covid-19 pandemic. Saf. Sci. 130:104870. doi: 10.1016/j.ssci.2020.104870

Vygotsky, L.S. (1978). Mind in Society: The Development of Higher Psychological Processes. London: Harvard University Press.

Wang, Q. (2010). Using online shared workspaces to support group collaborative learning. Comput. Educ. 55, 1270-1276. doi: 10.1016/j.compedu.2010.05.023

Williams, D. L., Crittenden, V. L., Keo, T., and McCarty, P. (2012). The use of social media: an exploratory study of usage among digital natives. J. Public Affairs 12, 127-136. doi: 10.1002/pa.1414

World Health Organization (2021). WHO Coronavirus (COVID-19) Dashboard. Available online at: https://covid19.who.int/ (assessed May 5, 2021).

Wu, J.-H., Chen, Y.-C., and Lin, L.-M. (2007). Empirical evaluation of the revised end user computing acceptance model. Comput. Hum. Behav. 23, 162-174. doi: $10.1016 /$ j.chb.2004.04.003

Conflict of Interest: The authors declare that the research was conducted in the absence of any commercial or financial relationships that could be construed as a potential conflict of interest.

Copyright (c) 2021 Khan, Ashraf, Seinen, Khan and Laar. This is an open-access article distributed under the terms of the Creative Commons Attribution License (CC $B Y)$. The use, distribution or reproduction in other forums is permitted, provided the original author(s) and the copyright owner(s) are credited and that the original publication in this journal is cited, in accordance with accepted academic practice. No use, distribution or reproduction is permitted which does not comply with these terms. 